\title{
Short-Term Effects of Pulsed Radiofrequency on Chronic Refractory Cervical Radicular Pain
}

\author{
Gyu-Sik Choi, M.D., Sang-Ho Ahn, M.D., Ph.D., Yun-Woo Cho, M.D., Ph.D., Dong-Kyu Lee, M.D.
}

Department of Rehabilitation Medicine, Yeungnam University College of Medicine, Daegu 705-717, Korea

\begin{abstract}
Objective To evaluate the short-term effectiveness of pulsed radiofrequency on the dorsal root ganglion (DRG) in patients with chronic refractory cervical radicular pain.

Method Fifteen patients (13 males, 2 females; mean age, 55.9 years) with chronic radicular pain due to cervical disc herniation or foraminal stenosis refractory to active rehabilitative management, including transforaminal cervical epidural steroid injection and exercise, were selected. All patients received pulsed radiofrequency on the symptomatic cervical dorsal root ganglion and were carefully evaluated for neurologic deficits and side effects. The clinical outcomes were measured using a visual analogue scale (VAS) and a neck disability index (NDI) before treatment, one and three months after treatment. Successful pain relief was defined as a $50 \%$ or greater reduction in the VAS score as compared with the pre-treatment score. After three months, we categorized the patients' satisfaction.

Results The average VAS for radicular pain was reduced significantly from 5.3 at pretreatment to 2.5 at 3 months post-treatment $(\mathrm{p}<0.05)$. Eleven of 15 patients $(77.3 \%)$ after cervical pulsed RF stimulation reported pain relief of $50 \%$ or more at the 3 month follow-up. The average NDI was significantly reduced from $44.0 \%$ at pretreatment to $35.8 \% 3$ months post-treatment $(\mathrm{p}<0.05)$. At 3 months post-treatment, eleven of fifteen patients $(73.3 \%)$ were satisfied with their status. No adverse effects were observed.

Conclusion The results demonstrate that the application of pulsed radiofrequency on DRG might be an effective short-term intervention for chronic refractory cervical radicular pain. Further studies, including a randomized controlled trial with long-term follow-up, are now needed.
\end{abstract}

Key Words Pulsed radiofrequency, Cervical radicular pain

Received September 6, 2010; Accepted Septemter 20, 2011

Corresponding author: Sang-Ho Ahn

Department of Rehabilitation Medicine \& Spine Center, Yeungnam University College of Medicine, 317-1, Daemyung-dong, Nam-gu, Daegu 705-717, Korea

Tel: +82-53-620-3268, Fax: +82-53-625-3508, E-mail: spineahn@yumail. ac.kr

(c) This is an open-access article distributed under the terms of the Creative Commons Attribution Non-Commercial License (http:// creativecommons.org/licenses/by-nc/3.0) which permits unrestricted noncommercial use, distribution, and reproduction in any medium, provided the original work is properly cited.

Copyright $\odot 2011$ by Korean Academy of Rehabilitation Medicine

\section{INTRODUCTION}

In a population of 100,000 persons, 83 will, on average, suffer from cervical radiculopathy every year. ${ }^{1}$ Radicular pain in the upper extremity is a form of neuralgia that is triggered by damage or irritation of sensory nerve roots located in the dorsal root ganglion of spinal nerves. This results in ectopic irritation in the dermatome controlled by the relevant nerves, which in turn is sensed as pain. ${ }^{2}$ By definition, radicular pain includes pain in areas 
beyond the spine and such pains are often described as ones that are sharp and stabbing, coming down along the arms. ${ }^{3}$ Cervical radiculopathy occurs by the compression of nerve roots, or by an inflammatory response in them, around the neural foramen. The most common causes are a herniated cervical disc or cervical foraminal stenosis. ${ }^{4}$

Biochemical factors that promote inflammatory responses in a nerve root include Phospholipase A2, interleukin-1 $\beta$, interleukin-6, tumor necrosis factor- $\alpha$ (TNF- $\alpha$ ), and interleukin-8. ${ }^{5-7}$ Steroids are reported to be substances that are engaged in suppressing these various inflammatory cytokines and chemokines. ${ }^{8,9}$ Recently, this knowledge has prompted the use of transforaminal epidural steroid injections performed with fluoroscopic control in patients with cervical radicular pain. Cyteval et al. ${ }^{10}$ reported a success rate of 60 percent with this technique.

In the 1980s, percutaneous radiofrequency treatment of dorsal root ganglia was introduced as one of the techniques to replace surgical rhizotomy in patients with chronic refractory radicular pain. ${ }^{11}$ Surgical rhizotomy had shown great short-term effects on patients with diverse pain syndromes, including those with chronic refractory radicular pain. ${ }^{12}$ However, this surgical technique was likely to trigger severe side effects due to the progression of the denervation over time. ${ }^{13}$ In contrast, percutaneous radiofrequency treatment of dorsal root ganglion coagulates only part of the dorsal root ganglia. It raises the threshold at which a harmful irritation is perceived as painful and reduces pain to a point that does not adversely affect normal sensation. ${ }^{14}$

Radiofrequency treatments are divided into continuous radiofrequency stimulation and pulsed radiofrequency stimulation using an electromagnetic field. Continuous radiofrequency treatment uses frictional heat arising from a catheter needle that is designed to deliver radiofrequency currents to surrounding tissues with only its needle tip. This induces heat coagulation of tissues in an excessively excited or morbid state, thereby blocking pain. However, complications from thermal injury induced by the radiofrequency waves sometimes lead to wide-ranging nerve destruction; therefore, continuous radiofrequency treatment has become a controversial choice of therapy. ${ }^{15,16}$ Recently, efforts have been made to circumvent these problems by using a pulsed radiofrequency treatment. These methods have evolved into short pulse radiofrequency treatments that use an electromagnetic field and pulsed radiofrequency treatments in which temperature is maintained at $42^{\circ} \mathrm{C}$ or below so that tissues are not damaged ${ }^{17} \mathrm{~A}$ recent study that induced a cervical dorsal root ganglion block in patients with chronic cervical radicular pain using pulsed radiofrequency reported that 7 of the 11 subjects experienced pain reduction of 50 percent or higher after 6 months. ${ }^{18}$

Radiofrequency treatment of dorsal root ganglia is becoming increasingly common in Europe and America. The application of this type of treatment to patients with cervical radicular pain in Korea has not yet been reported. Accordingly, the present study performed pulsed radiofrequency stimulation of domestic Korean patients who complained of chronic refractory cervical radicular pain and who had not obtained satisfactory treatment outcomes from many rounds of transforaminal epidural steroid injections and active rehabilitation treatment methods including exercise. The effectiveness of the radiofrequency treatment was examined during a three-month follow-up period.

\section{MATERIALS AND METHODS}

\section{Subjects}

A prospective follow-up study was conducted on fifteen patients (males: 12; females: 3 ) who presented with cervical radicular pain. This study included patients who had findings of neurological abnormalities such as radicular pain in a unilateral upper extremity, posterior neck pain, dysesthesia, and muscle weakness. The nerve root lesions predicted by their trigger symptoms had been discovered by magnetic resonance imaging (MRI) or computed tomography (CT), and results of electrophysiological findings were consistent with the results of imaging tests. The patients felt pain ordinarily and had experienced reduced pain after transforaminal epidural steroid injections with fluoroscopic control, but the effects of this treatment were not long-lasting or were unsatisfactory, and the level of pain did not change much for a minimum of 4 weeks after the final transforaminal epidural steroid injection. Among these 15 subjects, imaging tests revealed cervical soft disc herniation in 5 patients and spondylotic radiculopathy with cervical 
foraminal stenosis caused by hypertrophy of Luschka's joints or spinal facets in 10 patients (Fig. 1).

The subjects were $55.9 \pm 10.7$ years old, their period of complaint of pain before pulsed radiofrequency treatment was applied spanned 13.3 \pm 9.6 months, and their average number of nerve root steroid injections prior to pulsed radiofrequency treatment was three.

\section{Methods}

Pulsed radiofrequency stimulation: Pulsed radiofrequency treatment was performed aseptically. The subject was laid in the supine position under fluoroscopic control using a C-arm (Arcadis Orbic, Siemens, Ger- many). A 22-gauge cannula SMK Pole needle $54 \mathrm{~mm}$ long with a $4 \mathrm{~mm}$ active tip (Cotop International BV, Amsterdam, Netherland) was placed around the dorsal root ganglion that lie within the intervertebral foramen. The cannula was inserted over the caudal and posterior parts of the intervertebral foramen and its tip was placed at the border between the center and one third of the caudal part from the posterior neural foramen. The catheter needle was then inserted and positioned as near as possible to the dorsal root ganglion with the aid of a radiofrequency generator RFG-1A (Cosman Medical Inc., MA, USA), and a sensory stimulation test was performed. When abnormal sensation or pain was observed with a
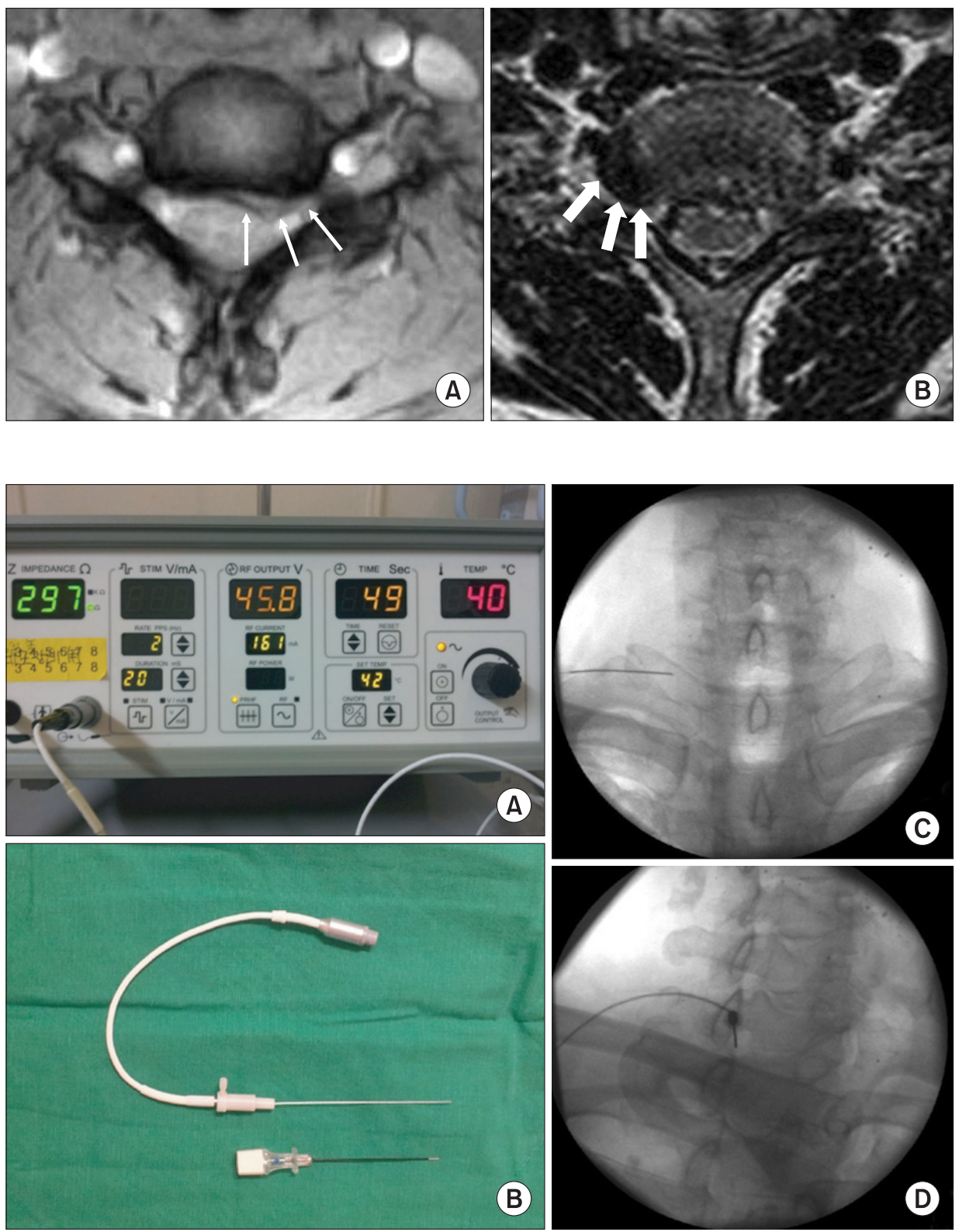

Fig. 1. These axial T2-weighted magnetic resonance images show an extruded disc (thin line arrow) in the left C5-6 paramedian area (A) and foraminal stenosis due to Luschka joint hypertrophy (thick line arrow) on the Right C6-7 level (B).
Fig. 2. (A) RF generator, (B) Cannula and Catheter needle, (C, D) Fluoroscopy-guided pulsed radiofrequency of the Right C8 dorsal root ganglion. 
stimulation of less than $0.3 \mathrm{~V}$, the catheter needle was considered to be placed near the dorsal root ganglion. When sensory stimulation was not achieved, the catheter needle was inserted more deeply into the intervertebral foramen until the subject complained of a dull pain; however, the needle was not inserted beyond the lateral half of the articular mass seen on an anteroposterior view. The radiofrequency generator was set so that the temperature of the catheter needle tip would not exceed $42^{\circ} \mathrm{C}$ and a radiofrequency magnetic field was applied at $45 \mathrm{~V}$ for 120 seconds (Fig. 2).

Outcome measurements: A visual analog scale (VAS) was used to measure the intensity of the subjects' pain and the neck disability index (NDI) was used to evaluate the functions affected by this pain. These measurements were obtained prior to treatment and one and three months after treatment. The NDI consisted of 10 items - the intensity of pain, personal management (bathing and putting on clothes), raising objects, reading books, headache, concentration, working, driving, sleeping, and leisure activities. The score for each item was zero to five points and the total score ranged from zero to 50 points. An NDI score was calculated from the total of the scores for each item. A high NDI score indicated a more severe functional disability related to the cervical abnormality. In this study, the severity of functional disabilities due to pain was represented by a percentage (\%) (disability in percent $=($ total score $) / 50 \times 100)$. A successful treatment was defined as a reduction in pain of 50 percent or more compared with the VAS score prior to the treatment. Three months after pulsed radiofrequency treatment was performed, the subjects' degree of satisfaction with the treatment was recorded as "excellent," "good," "fair," or "poor." "Excellent" meant that the subject's level of satisfaction with treatment results was equal to his or her expectation. "Good" meant that although the subject's level of satisfaction was not up to his or her expectation, the subject was willing to receive treatment in case of another attack of pain. "Fair" meant that although the treatment was not ineffective, the subject was unwilling to opt for this treatment in case of another attack of pain. "Poor" meant that this treatment effect was similar to or worse than prior treatment effects. A third party who was blinded to the patients' conditions and treatment history evaluated questionnaires on pain and degree of satisfaction with treatment. ${ }^{19}$ SPSS 18.0 software was used for statistical analysis. Repeated measures of one factor analysis was employed to compare differences between time points through a contrast test to determine clinical progression. Significance was reached if the $p$-value was less than 0.05 .

\section{RESULTS}

\section{Changes in the VAS of pain in the upper extremity}

The VAS of pain in the upper extremity was an average of $5.3 \pm 1.4$ prior to pulsed radiofrequency treatment and this score significantly decreased to $2.7 \pm 1.9$ at one month after the treatment, and to $2.5 \pm 1.9$ at 3 months after the treatment ( $\mathrm{p}<0.05)$ (Fig. 3). The VAS score of 11 (73.3\%) of the 15 patients was reduced by more than $50 \%$ compared with scores prior to treatment, indicating a successful reduction in pain. However, the other three patients showed no response at all to pulsed radiofrequency treatment (Fig. 4).

\section{NDI}

The NDI score averaged $44.0 \pm 15.3 \%$ before treatment and decreased to $37.0 \pm 15.8 \%$ and $35.8 \pm 15.7 \%$, respectively, one and three months after treatment $(\mathrm{p}<0.05)$ (Fig. 5).

\section{Subjects' satisfaction with the treatment}

After three months of pulsed radiofrequency treatment, the number of patients who answered "excellent," "good,"

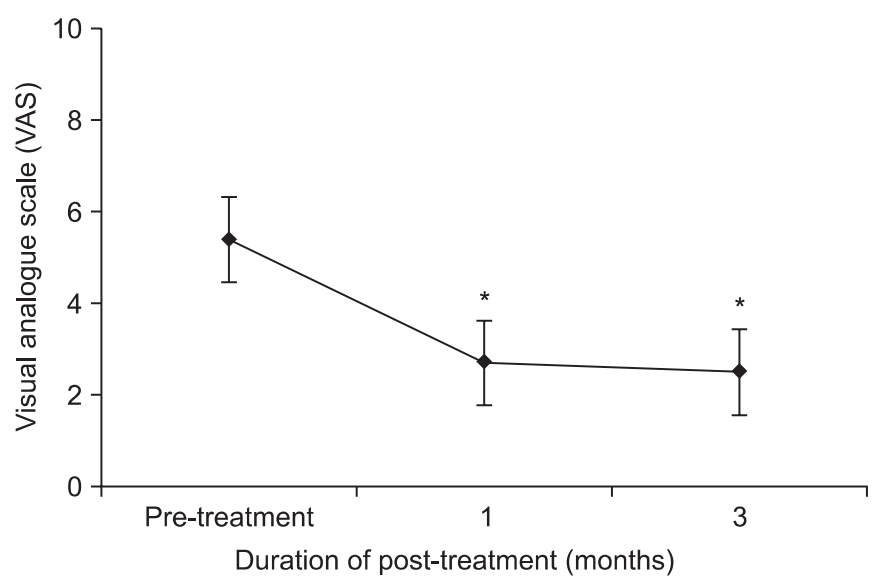

Fig. 3. Scores of the visual analogue scale (VAS) for cervical radicular pain were reduced significantly from 5.3 at pretreatment to 2.7 at 1 month post-treatment, and to 2.5 at 3 months post-treatment, respectively. ${ }^{*} \mathrm{p}<0.05$ : Compared with pre-treatment. 




Fig. 4. Individual changes in visual analogue scale (VAS) scores versus time: pre-treatment, and 1 and 3 months posttreatment.

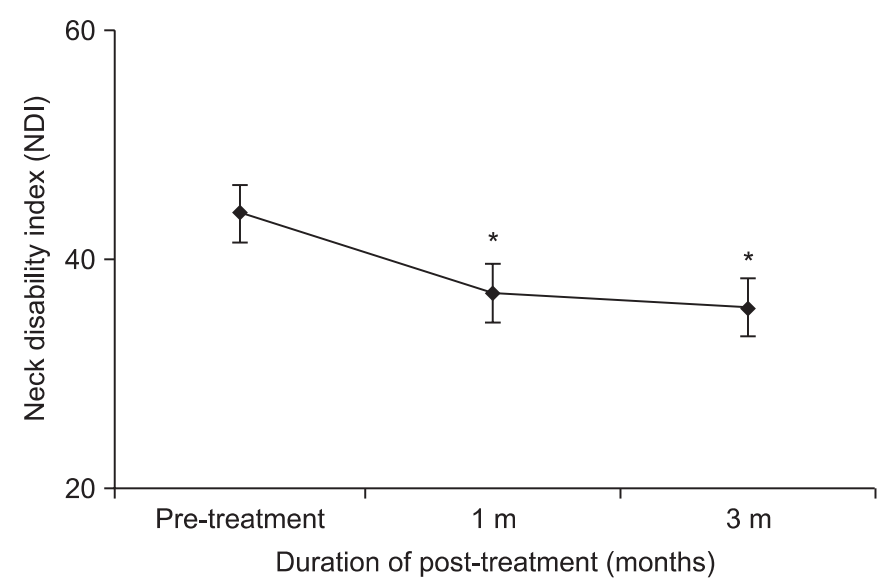

Fig. 5. Average Neck disability index (NDI) was reduced significantly from $44.0 \%$ at pre-treatment to $35.8 \%$ at 3 months post-treatment. ${ }^{*} \mathrm{p}<0.05$ : Compared with pre-treatment.

"fair," and "poor" was $46.7 \%, 26.7 \%, 13.3 \%$, and $13.3 \%$, respectively, and $73.3 \%$ of the subjects indicated positive responses such as "excellent" or "good".

\section{DISCUSSION}

In this study we administered pulsed radiofrequency treatment to chronic cervical radicular pain patients who had not obtained satisfactory treatment effects from several transforaminal epidural steroid injections with fluoroscopic control. The patients were then prospectively followed for three months. The patients' VAS of radicular pain and NDI significantly decreased from one month after the treatment and decreased further at 3 months. In total, $73.3 \%$ of the patients responded that the result was "excellent" or "good".

In general, radicular pain is explained by a mechanism in which the nerve roots are damaged by compression of their surrounding structures. The resulting ischemia ${ }^{20}$ or the inflammatory responses that occur near nerve roots due to the release of inflammatory mediators from a herniated nucleus pulposus then triggers the damage in nerve roots. ${ }^{21}$ Recent studies verified that epidural steroid injections have noticeable effects in treating radicular pain originating from cervical disc disease and this treatment shows continuous efficacy for more than 6 months. ${ }^{22}$ However, 20 to 40 percent of steroid-treated patients do not experience a satisfactory reduction in pain $^{23,24}$ and therefore other therapeutic approaches are needed.

Most reports have dealt with surgical approaches. ${ }^{25,26} \mathrm{~A}$ representative non-surgical approach is radiofrequency treatment. In the 1980s, attempts were made to apply continuous radiofrequency treatment to patients with chronic refractory radicular pain. Thereafter, pulsed radiofrequency treatment was performed on these patients in order to decrease secondary nerve damage. ${ }^{17,27}$ This technique does not cause a temperature rise that would be destructive to nerves ${ }^{17}$ and it is considered to be a more appropriate method for treating refractory pain resulting from radiculopathy compared to neurodestructive procedures. A recent study that examined the treatment effects of pulsed radiofrequency techniques on patients with radicular pain (due to herniated intervertebral disc or previous failed surgery) reported that $53 \%$ of patients with cervical radicular pain and $51 \%$ of those with lumbar radicular pain experienced a reduction in pain of more than $50 \%$ one week after treatment. In addition, $55 \%$ of those with cervical radicular pain and $45 \%$ of those with lumbar radicular pain experienced pain reduction of more than $50 \%$ three months after treatment. ${ }^{28}$ Another study reported that 7 of 11 patients with chronic cervical radicular pain who underwent a dorsal root ganglion block using pulsed radiofrequency experienced reductions in pain of more than $50 \%{ }^{18}$ In the present study, 11 of the 15 patients with chronic refractory cervical radicular pain who underwent pulsed radiofrequency stimulation of the cervical dorsal 
root ganglion had their pain reduced by more than $50 \%$ three months after the procedures, suggesting short-term efficacy for this treatment.

The mechanism of pain regulation by pulsed radiofrequency stimulation has yet to be discovered. ${ }^{14}$ Higuchi et al. ${ }^{29}$ performed an experiment in which pulsed radiofrequency and continuous radiofrequency stimulation were administered to the dorsal root ganglion of mice. Only pulsed stimulation increased c-Fos expression. Similarly, van Zundert et al. ${ }^{30}$ observed an increase in c-Fos expression in the dorsal root ganglion of mice seven days after continuous radiofrequency stimulation at $67^{\circ} \mathrm{C}$ or pulsed radiofrequency stimulation at less than $42^{\circ} \mathrm{C}$. The clinical relationship between c-Fos expression and pain alleviation has not yet been determined and additional research is necessary to examine expression of pain-related factors through methods like immunochemical staining. In the present study, treatment effects observed in the first month after pulsed radiofrequency treatment continued until the third month, showing a short-term effect. No specific complications were observed during the follow-up period, suggesting that pulsed radiofrequency treatment is relatively safe for cervical radicular pain patients.

This study's limitation is that pulsed radiofrequency treatment was performed on all chronic cervical radicular pain patients who met the study criteria, without establishing any control group. Therefore, future research with a control group and long-term follow-up (more than 1 year) are necessary to validate the present findings. The number of subjects enrolled in the present study was small and future prospective follow-up studies will also need to study a greater number of patients.

\section{CONCLUSION}

Pulsed radiofrequency stimulation was performed on patients who complained of chronic refractory cervical radicular pain and who had not obtained satisfactory treatment outcomes from many rounds of transforaminal epidural steroid injections. Pulsed radiofrequency treatment of dorsal root ganglion had a good short-term antinociceptive effect that continued for three months. In $73.3 \%$ of the patients, their VAS scores were reduced by more than $50 \%$ by the treatment and they responded that the treatment effect was "excellent" or "good."
Pulsed radiofrequency treatment could be applied as a secondary treatment method for patients with chronic radicular pain due to cervical herniated disc or cervical foraminal stenosis who do not experience satisfactory treatment effects from transforaminal epidural steroid injections.

\section{ACKNOWLEDGEMENTS}

This study was supported by a grant of the Korea Healthcare technology R\&D Project, Ministry for Health, Welfare \&Family Affairs, Republic of Korea (A084177).

\section{REFERENCES}

1. Radhakrishnan K, Litchy WJ, O'Fallon WM, Kurland LT. Epidemiology of cervical radiculopathy. A population-based study of Rochester, Minnesota, 1976 through 1990. Brain 1994; 117: 325-335

2. Rathmell JP, Aprill C, Bogduk N. Cervical transforaminal injection of steroids. Anesthesiology 2004; 100: 1595-1600

3. Merskey H, Bogduk N. Classification of chronic pain, 2nd ed, Seattle: IASP Press, 1994, 209-221

4. Ahlgren B, Garfin S. Cervical radiculopathy. Orthop Clin North Am 1996; 27: 253-263

5. Takahashi H, Suguro T, Okazima Y, Motegi M, Okada Y, Kakiuchi T. Inflammatoy cytokines in the herniated disc of the lumbar spine. Spine 1996; 21: 218-224

6. Ahn SH, Cho YW, Ahn MH, Jang SH, Sohn YK, Kim HS. mRNA expression of cytokines and chemokines in herniated lumbar intervertebral discs. Spine 2002; 27 : 911-917

7. Saal JS, Franson RC, Dobrow R, Saal JA, White AH, Goldthwaite N. High levels of inflammatory phospholipase A2 activity in lumbar disc herniations. Spine 1990; 15: 674-678

8. Olmarker K, Byrod G, Cornefjord M, Nordborg C, Rydevik B. Effects of methylprednisolone on nucleus pulposus-induced nerve root injury. Spine 1994; 19: 1803-1808

9. Shishido H, Kikuchi S, Heckman H, Myers RR. Dexamethasone decreases blood flow in normal nerves and dorsal root ganglia. Spine 2002; 27: 581 586

10. Cyteval C, Thomas E, Decoux E, Sarrabere MP, Cottin 
A, Blotman F, Taourel P. Cervical radiculopathy: open study on percutaneous periradicular foraminal steroid infiltration performed under CT control in 30 patients. AJNR Am J Neuroradiol 2004; 25: 441-445

11. Pagura JR. Percutaneous radiofrequency spinal rhizotomy. Appl Neurophysiol 1983; 46: 138-146

12. Loeser JD. Dorsal rhizotomy for the relief of chronic pain. J Neurosurg 1972; 36: 745-750

13. North RB, Kidd DH, Campbell JN, Long DM. Dorsal root ganglionectomy for failed back surgery syndrome: a 5-year follow-up study. J Neurosurg 1991; 74: 236-242

14. van Wijk RM, Geurts JW, Wynne HJ. Long-lasting analgesic effect of radiofrequency treatment of the lumbosacral dorsal root ganglion. J Neurosurg 2001; 94 Suppl 2: 227-231

15. Vatansever D, Tekin I, Tuglu I, Erbuyun K, Ok G. A comparison of the neuroablative effects of conventional and pulsed radiofrequency techniques. Clin J Pain 2008; 24: 717-724

16. Heavner JE, Boswell MV, Racz GB. A comparison of pulsed radiofrequency and continuous radiofrequency on thermocoagulation of egg white in vitro. Pain Physician 2006; 9: 135-137

17. Sluijter M, Cosman E, Rittman W, van Kleef M. The effects of pulsed radiofrequency field applied to the dorsal root ganglion: a preliminary report. Pain Clinic 1998; 11: 109-117

18. Van Zundert J, Patijn J, Kessels A, Lame I, van Suijlekom H, van Kleef M. Pulsed radiofrequency adjacent to the cervical dorsal root ganglion in chronic cervical radicular pain: a double blind sham controlled randomized clinical trial. Pain 2007; 127: 173-182

19. Slipman CW, Lipetz JS, DePalma MJ, Jackson HB. Therapeutic selective nerve root block in the nonsurgical treatment of traumatically induced cervical spondylotic radicular pain. Am J Phys Med Rehabil 2004; 83: 446-454

20. Kobayashi S, Yoshizawa H, Yamada S. Pathology of lumbar nerve root compression. Part 1: Intraradicular inflammatory changes induced by mechanical com- pression. J Orthop Res 2004; 22: 170-179

21. Doita M, Kanatani T, Harada T, Mizuno K. Immunohistologic study of the ruptured intervertebral disc of the lumbar spine. Spine 1996; 21: 235-241

22. Benyamin RM, Singh V, Parr AT, Conn A, Diwan S, Abdi S. Systematic review of the effectiveness of cervical epidurals in the management of chronic neck pain. Pain Physician 2009; 12: 137-157

23. Slipman CW, Lipetz JS, Jakson HB, Rogers DP, Vresilovic EJ. Therapeutic selective nerve root block in the nonsurgical treatment of atraumatic cervical spondylotic radicular pain: a retrospective analysis with independent clinical review. Arch Phys Med Rehabil 2000; 81: 741-746

24. Saal JS, Saal JA, Yurth EF. Nonoperative management of herniated cervical intervertebral disc with radiculopathy. Spine 1996; 21: 1877-1883

25. Arnasson O, Carlsson CA, Pellettieri L. Surgical and conservative treatment of cervical spondylotic radiculopathy and myelopathy. Acta Neurochir (Wien) 1987; 84: 48-53

26. Lees F, Turner JW. Natural history and prognosis of cervical spondylosis. Br Med J 1963; 2: 1607-1610

27. Mikeladze G, Espinal R, Finnegan R, Routon J, Martin D. Pulsed radiofrequency application in treatment of chronic zygapophyseal joint pain. Spine J 2003; 3: 360362

28. Chao SC, Lee HT, Kao TH, Yang MY, Tsuei YS, Shen CC, Tsou HK. Percutaneous pulsed radiofrequency in the treatment of cervical and lumbar radicular pain. Surg Neurol 2008; 70: 59-65

29. Higuchi Y, Nashold BS Jr, Sluijter M, Cosman E, Pearlstein RD. Exposure of the dorsal root ganglion in rats to pulsed radiofrequency currents activates dorsal horn lamina I and II neurons. Neurosurgery 2002; 50: 850-855

30. van Zundert J, de Louw AJ, Joosten EA, Kessels AG, Honig W, Dederen PJ, Veening JG, Vles JS, van Kleef M. Pulsed and continuos radiofrequency current adjacent to the cervical dorsal root ganglion of the rat induces late cellular activity in the dorsal horn. Anesthesiology 2005; 102: 125-131 